\title{
Multidisciplinary approach to giant paratesticular liposarcoma
}

\author{
Raquel Sopeña-Sutil, MD; ${ }^{1}$ Francesco Silan, MD; ${ }^{2}$ Maria Teresa Butron-Vila, MD; ${ }^{3}$ Felix Guerrero-Ramos, MD; \\ Emilio Lagaron-Comba, MD;' Juan Passas-Martinez, $M D^{\prime}$
}

Urology Department; 2 Plastic and Reconstructive Surgery Department; ${ }^{3}$ General Surgery Department; Hospital Universtario 12 de Octubre, Madrid, Spain

Cite as: Can Urol Assoc J 2016;10(9-10):E316-9. http://dx.doi.org/10.5489/cuai.3346 Published online September 13, 2016

\section{Abstract}

Primary paratesticular tumours are very rare and the spermatic cord (SCT) is the most frequent site of origin, with $20 \%$ of malignancy. Although liposarcoma is the most frequent histotype (46.6\%), less than 200 cases have been reported in the literature.

We report the case of a 56-year-old man who presented a giant scrotal mass of 25 years of evolution and measuring $40 \times 40 \mathrm{~cm}$. It could be considered the greatest paratesticular liposarcoma described to date. Computed tomogaphy $(\mathrm{CT})$ revealed mass features consistent with liposarcoma and the simultaneous presence of bilateral inguinal hernia with bladder involvement. A multidisciplinary approach was taken to remove the mass, solve the hernia, and provide functional results.

\section{Introduction}

Primary paratesticular tumours are very rare and the spermatic cord (SCT) is the most frequent site of origin (over $75 \%$ ). The incidence of SCT is 0.3 cases per million men per year, with $20 \%$ of cases being malignant. They usually present as unilateral, firm, slow-growing masses and their size ranges from $1.5-30 \mathrm{~cm}$. Although liposarcoma is the most frequent histotype among malignant tumours (46.6\%), to the best of our knowledge, less than 200 cases have been reported in the literature. ${ }^{1}$

\section{Case report}

A 56-year-old man presented with a painless swelling in his scrotum that had been slowly growing over a period of 25 years. The size of the mass prevented him from walking. The physical examination revealed a huge, firm, inguinoscrotal mass that reached the knees. The size of the mass prevented him from walking, mantaining proper higiene, and leading a normal life (Fig. 1).
An abdomino-pelvic computed tomography (CT) scan suggested the diagnosis of liposarcoma. The left testis was shifted towards the midline. An evident left varicocele and multiple inguinal lymphadenopathies were found as well. Bilateral inguinoscrotal hernia was present, with the right side containing sigmoid colon and most of the bladder (Fig. 2).

The blood analysis showed tumour markers in normal range (beta-human chorionic gonadotropin [ $\beta$-hCG], lactate dehydrogenase [LDH], and alpha-fetoprotein [AFP]).

A multidisciplinary approach was taken, combining the expertise of urologists, plastic surgeons, and general surgeons. The aim was to solve every issue (scrotal mass exeresis, abdominal wall repair, buried penis repair, defect reconstruction) with a single surgery.

A multistep surgery was carried out and the entire procedure lasted 420 minutes. Steps included: 1) incision of the prepuce to visualize the penis and catheterized the urethra with Foley catheter; 2) right inguinal transversal incision (resection of the large sac of direct hernia M3 (EHS) with all of the sigmoid colon and bladder; hernioplasty with two low-density polypropilene meshes [preperitoneal and anterior]; 3 ) resection of a large tumour (location and ligation of left spermatic cord in the inguinal canal; wide excision of scrotal mass of $40 \times 40 \mathrm{~cm}$ and $29 \mathrm{~kg}$, including scrotal skin and left testicle [which was surrounded by mass] [Fig. 3]); appearance of heterogeneous tumour with abundant neoangiogenesis, requiring careful ligation lot of veins; 4) circumcision and repair of ventral side of the penis with Byars flap; 5) we found a left inguinal hernia M1 (EHS) repaired by Lichtenstein hernioplasty; and 6) lithotomy position, right testicle is coverd with preserved scrotal skin; closing perineal defect with Z-plasty (Fig. 4.)

As postoperative complications, the patient developed a Klebsiella pneumoniae and an Enterobacter cloacae infection at the surgical site, which required intravenous antibiotic treatment.

The histopathologic exam showed a well-differentiated liposarcoma with spindle and lipoma-like cells (Grade 1), without infiltration of the testis and with free surgical margins. (Immunohistochemistry: Collagen type IV, vimentin, 


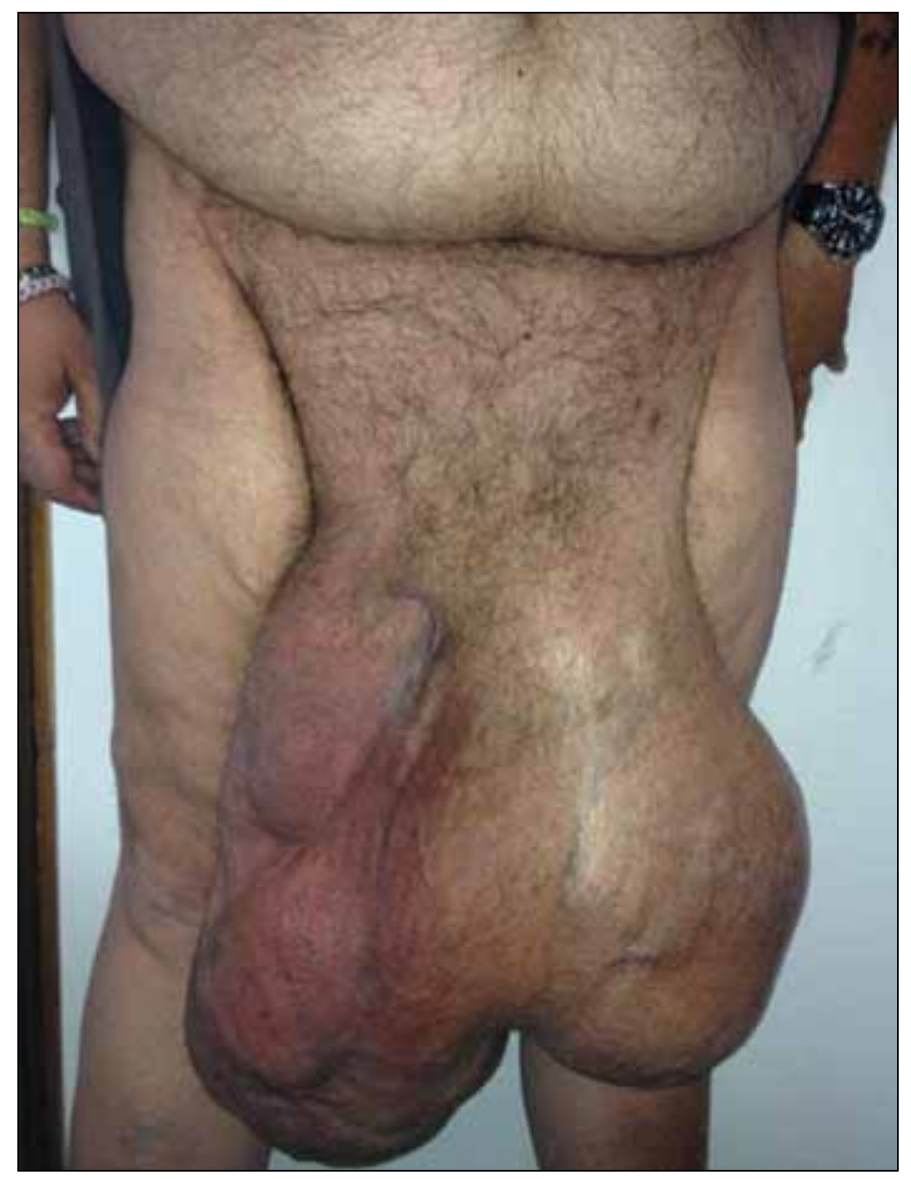

Fig. 1. Inguinoescrotal mass reaches a size of $40 \times 40 \mathrm{~cm}$ and a weight of 29 $\mathrm{kg}$. This is a solid, and in some locations petrous, consistency with abundant collateral circulation. The testicles can not be located and the penis is completely covered.

nuclear MDM2 positivity, BCL-2, CD99, CD34 focal positivity.)

Six months after surgery, the patient regained mobility and quality of life; $\mathrm{CT} /$ magnetic resonance imaging (MRI) reveal no tumour recurrence.

\section{Discussion}

Primary paratesticular tumours are very rare and while SCT is the most frequent site of origin, incidence is low, as is malignancy. ${ }^{1}$ Malignant tumours have sarcomatoid lineage in more than $90 \%$ of cases because they are derived from mesoderm. Overall, sarcomas represent less than $2 \%$ of genitouninary tumours and $30 \%$ of them are located in the spermatic cord. Histologically, the most frequent are liposarcomas, followed by leiomyosarcomas and rhabdomyosarcoma. ${ }^{2,3}$

Less than 200 cases of paratesticular liposarcoma have been reported in literature. ${ }^{3}$ Due to its rarity, consensus on risk, prognostic factors, and management is difficult to achieve.

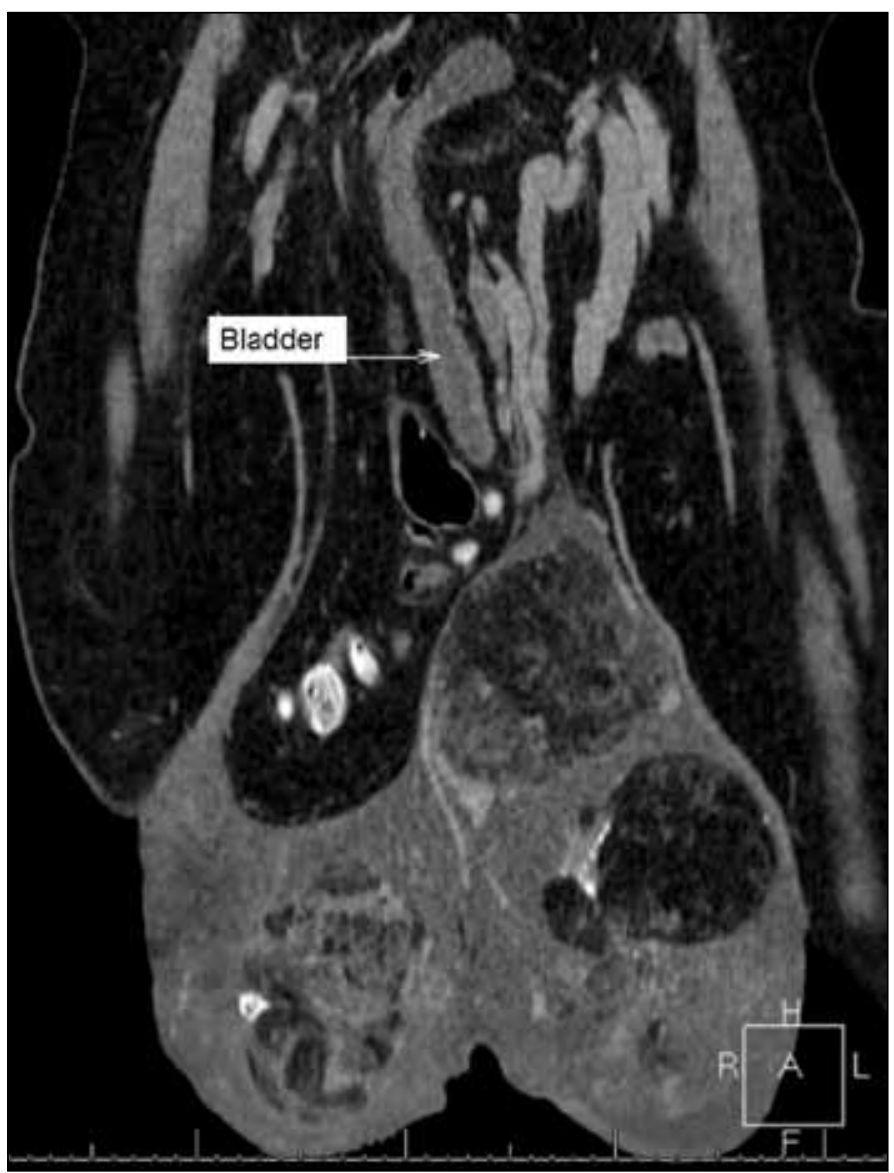

Fig. 2. Computed tomography showed huge polylobulated fibrofatty mass in the left hemiscrotum that was compatible with liposarcoma. In the picture, the herniated bladder is observed.

These tumours appear as firm, unilateral, unpainful masses. The overall median patient age was 58 years (range 16-83 years). ${ }^{4}$ At the beginning, the mass may be confounded with cord cysts, hidrocele, or epididimitis; later, it may be mistaken with an inguinal hernia (as in our case, in which both entities coexist). In addition, its slow growth suggests a benign origin. All this can delay treatment. ${ }^{4}$

The size of the masses reported ranges between 1.5 and $23 \mathrm{~cm}$, weighing up to $13 \mathrm{~kg}$ in a review published by García Morúa et $\mathrm{l}^{5}$ Our case could be considered the largest paratesticular liposarcoma described to date.

There are no pathognomonic features in the imaging, but $\mathrm{CT}$ and MRI provide information about tissue characteristics, margins, and lymph node involvement, as well as visceral metastases.

Classification of liposarcoma has been described according to histological features, which establishes four subtypes: lipoma-like, myxoid differentiation, pleomorphic, and dedifferentiated liposarcoma. Most paratesticular liposarcomas (40-45\%) are well-differentiated histopathologic subtype (lipoma-like). ${ }^{5}$ 


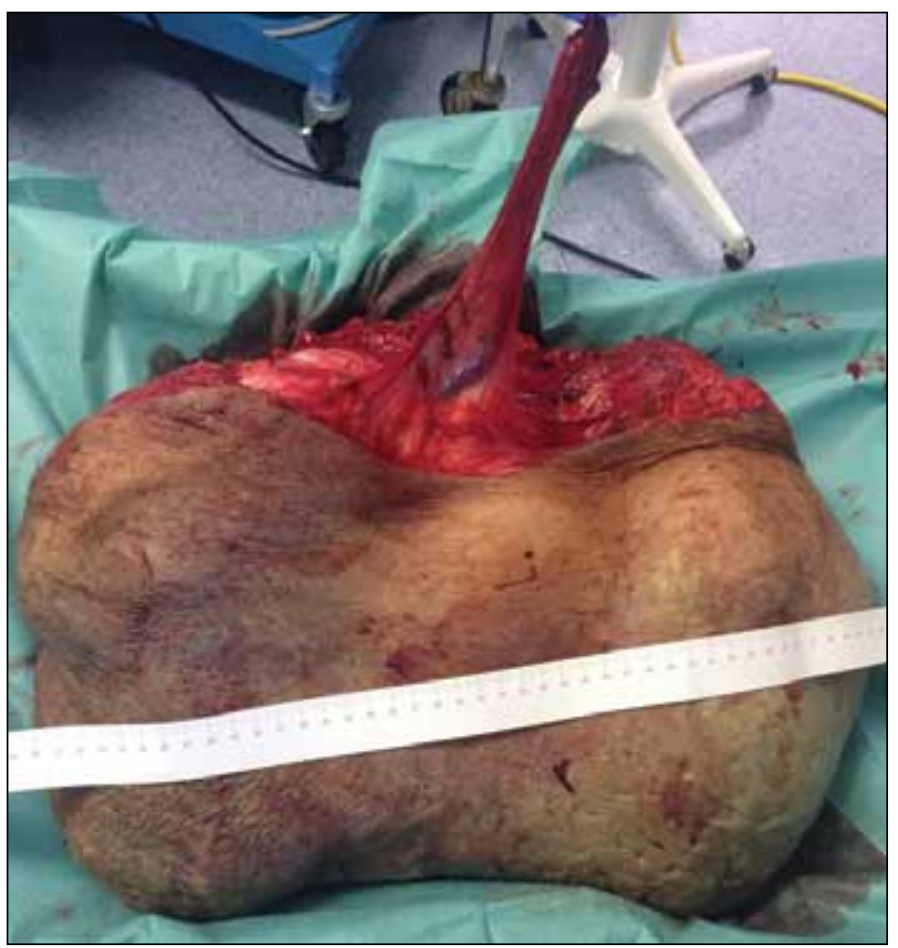

Fig. 3. Specimen sent to pathology that includes letf testicle, spermatic cord, and scrotal mass.

The treatment is surgical removal: wide excision of the tumour with ipsilateral orchidectomy and ligation of the cord in the inguinal canal. The regional lymphadenectomy has shown no benefit and is, therefire, recommended only in selected cases. ${ }^{2,6}$

The prognosis is influenced by several conditions, such as the surgical margins or the histological type and grade..$^{6-8}$

The role of adjuvant radiotherapy and/or chemotherapy is controversial. Some authors support radiotherapy treatment in all cases, justifying the high radiosensitivity of these tumours and the high rate of local recurrence. Because there are no conclusive data, radiotherapy is proposed if there are positive surgical margins, high histological grade, or local recurrence. Chemotherapy is indicated in dedifferentiated or metastatic tumours. ${ }^{2,9,10}$

Prolonged monitoring is essential for the proper management of these patients due to the possibility of recurrence and late metastasis.

\section{Conclusion}

Cord liposarcoma is a rare disease. Complete excision is essential for proper treatment. The multidisciplinary approach is necessary in giant masses to achieve good oncological and functional results.

Competing interests: The authors report no competing personal or financial interests.

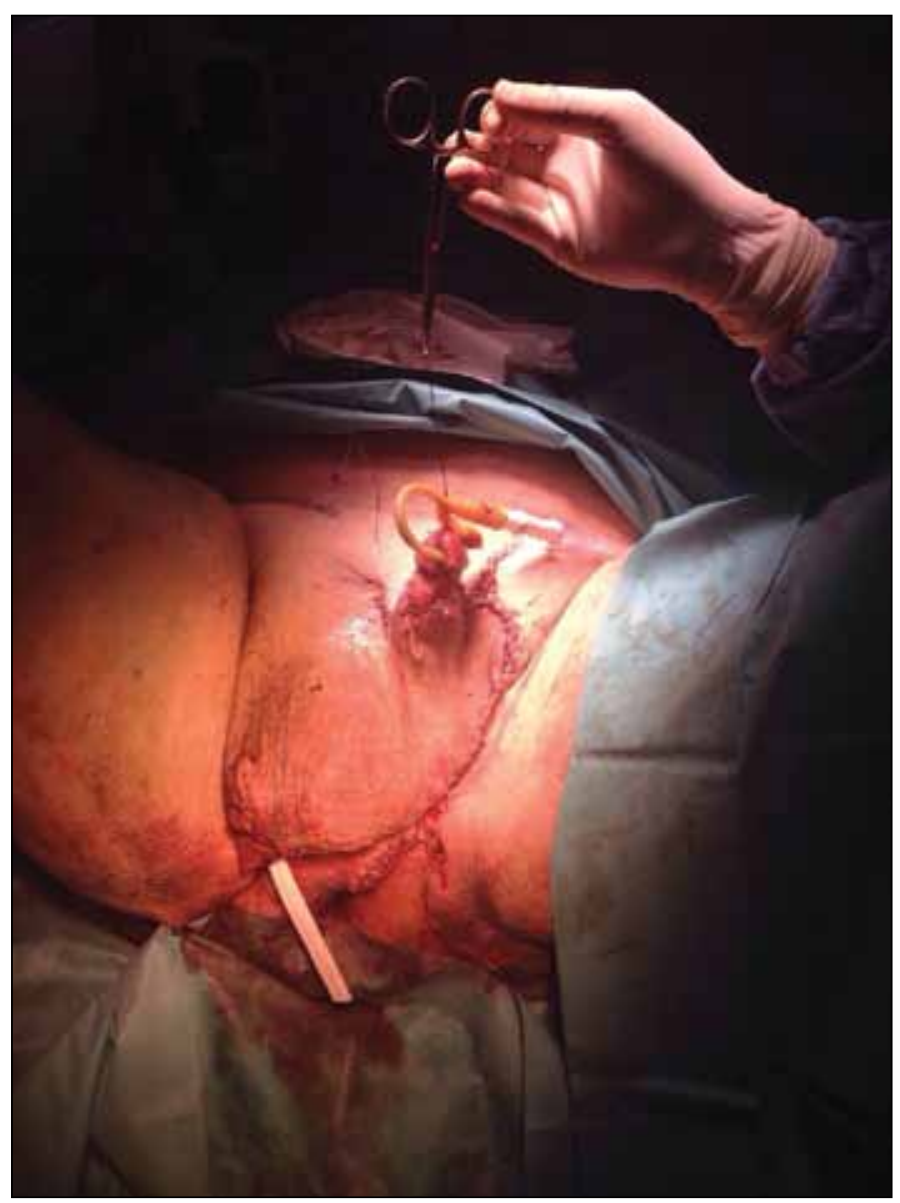

Fig.4. Final result of the surgery: Externalized penis, right testicle preserved, and scrotal reconstruction.

This paper has been peer-reviewed.

\section{References}

1. Rodríguez D, Barrisford GW, Sanchez A, et al. Primary spermatic cord tumours: Disease characteristics, prognostic factors, and treatment outcomes. Uro Oncol 2014;32:19-25. http://dx.doi.org/10.1016/i. urolonc.2013.08.009

2. Rodríguez D, Olumi AF. Management of spermatic cord tumours: A rare urologic malignancy. Ther Adv Urol 2012;4:325-34. http://dx.doi.org/10.1177/1756287212447839

3. Vinayagam K, Hosamath V, Honnapp $S$, et al. Paratesticular liposarcoma masquerading as a testicular tumour. J Clin Diagn Res 2014;8:165-6.

4. Coleman J, Brennan MF, Alektiar K, et al. Adult spermatic cord sarcomas: Management and results. Ann Surg Oncol 2003;10:669-75. http://dx.doi.org/10.1245/ASO.2003.11.014

5. García Morúa A, Lozano Salinas JF, Valdés Sepúlveda F, et al. Liposarcoma del cordón espermático: Nuestra experiencia y revisión de la literatura. Actas Urol Esp 2009;33:811-5. http://dx.doi.org/10.1016/ S0210-4806(09)74235-4

6. Radaelli S, Desai A, Hodson J, et al. Prognostic factors and outcome of spermatic cord sarcoma. Ann Surg Oncol 2014;21:3557-63. http://dx.doi.org/10.1245/s10434-014-3751-1

7. Kooby DA, Antonescu CR, Brennan MF, et al. Atypical lipomatous tumour/well-differentiated liposarcoma of the extremity and trunk wall: Importance of histological subtype with treatment reccomendations. Ann Surg Oncol 2004;11:78-84. http://dx.doi.org/10.1007/BF02524350

8. Brooks AD, Bowne WB, Delgado $R$, et al. Soft tissue sarcoma of the groin: Diagnosis, management, and prognosis. J Am Coll Surg 2001;193:130-6. http://dx.doi.org/10.1016/S1072-7515(01)00982-6 
9. Ballo MT, Zagars GK, Pisters PW, et al. Spermatic cord sarcoma: Outcome, patterns of failure, and management. J Urol 2001;166:1306-10. http://dx.doi.org/10.1016/S0022-5347(05)65758-8

10. Raney RB, Walterhouse DO, Meza JL, et al. Results of the Intergroup Rhabdomyosarcoma Study Group D9602 Protocol, using vincristine and dactinomycin with or without cyclophosphamide and radiation therapy, for newly diagnosed patients with low-risk embryonal rhabdomyosarcoma: A report from the Soft Tissue Sarcoma Committee of the Children's Oncology Group. J Clin Oncol 2011;29: 1312-8. http:// dx.doi.org/10.1200/JC0.2010.30.4469
Correspondence: Dr. Sopeña-Sutil, Urology Department, Hospital Universtario 12 de Octubre, Madrid, Spain; raquelsopenasutil@gmail.com 